Koh, N.K. and Fraser, B. 2014. Learning environment associated with use of mixed mode delivery model among secondary business studies students in Singapore. Learning Environment Research. 17 (2): pp. 157-171.

Learning environment associated with use of mixed mode delivery model among secondary business studies students in Singapore

Koh Noi Keng and Barry J. Fraser

Contact Author: $\quad$ Barry Fraser

Koh Noi Keng ( $\square$ ) - Barry Fraser

KOH Noi Keng

National Institute of Education

1 Nanyang Walk

Singapore

Barry Fraser

Science and Mathematics Education Centre

Curtin University

GPO Box U1987

Perth WA 6845

Australia 


\title{
Learning environment associated with use of mixed mode delivery model among secondary business studies students in Singapore
}

Initial Date Submitted:

Status Date (Cond. Accepted)

\begin{abstract}
Because the attention span of students is short, educational reforms need to sustain students' interest and engage them in learning. At Singapore's national teacher education institute, preservice teachers are empowered to use pedagogical tools and strategies that engage their students. We used a version of the Constructivist Learning Environment Survey (CLES) to evaluate the effectiveness of a pedagogical model known as the Mixed Mode Delivery (MMD) model. Comparisons were made between 2216 secondary school students taught by the preservice teachers in an MMD group and 991 students in a control group in terms of the relative magnitudes of the gap between the actual and preferred learning environment in students' school classrooms. The findings supported the positive impact of using MMD in terms of students' perceptions of their classroom environments.
\end{abstract}

Keywords: Business studies; Constructivist Learning Environment Survey (CLES); evaluation; learning environments; mixed mode delivery; Singapore.

\section{Introduction}

This study involved evaluating the learning environment of school classrooms whose teachers used a Mixed Mode Delivery (MMD) pedagogical framework (Koh 2004) for capitalising on new knowledge technologies to meet the needs of different types of learners and, more importantly, to build a more learner-centred, process-oriented and skills-focused approach to teaching (Tapscott 
1997). As new technologies open up new opportunities, educators are seeking new ways to engage learners in meaningful learning involving challenging and real-life tasks and to capitalise on technology as a tool for learning and collaboration.

The MMD provides a pedagogical model to mix and match engaging teaching and learning strategies to meet the demands of learners. Basically, it involves a variety of constructivist approaches to teaching and learning, with each activity lasting only for about 10 minutes or so, with another strategy or activity or mode of learning following. Constructivists recognise that learning occurs not in a vacuum but is embedded in a particular social setting or learning environment (Duit and Treagust 1995). The MMD involves a constructivist approach to learning and emphasises student-centred learning.

Because of the potential of the MMD model as a useful framework for effective teaching and learning, we decided to investigate its usefulness as perceived by learners. Consequently, the overarching research question "What is the impact of using the MMD on the nature of a learning environment?" was operationalised by measuring school students' perceptions of their learning environment. Our research did not focus on one particular kind of computer usage or tool but, rather, the use of a pedagogical framework that involved a broad array of teaching and learning strategies in an outcomes-focused, technology-rich environment.

The MMD model embraces a wide variety of methodologies, which include cooperative learning, case studies, field trips, problem-based learning and strategies that are ICT-based, such as WebQuest, mind-tools, e-learning, video vignettes, online games and internet-based discussion forums. The class dynamics and the teaching and learning styles are different from traditional teaching methods. Also, there must be authentic and purposeful tasks to bridge the gap between education and the world of work (Rainer \& Matthews, 2002). Andrews, Garrison and Magnusson (1996) found in their interviews probing teaching excellence at the tertiary level that "the general concept ... expressed was that excellent teachers use self-reflection to develop a model (either formal 
or informal) for teaching within a particular context: they then attempt to 'live the model', and be authentic to and congruent with their model" (p. 87). These ideas are embedded in the MMD model.

\section{Background and rationale}

Traditionally research and evaluation in education have tended to rely heavily on the assessment of academic achievement. Although the value of outcome measures cannot be disputed, they cannot give a complete picture of the educational process (Fraser 1994, 2012). Research findings have consistently shown that students' and teachers' perceptions of important social and psychological aspects of the learning environments really matter in terms of educational outcomes. Moreover, other literature (Entwistle 1991) shows that instructional practices do not have a direct impact on learning and, instead, might be 'distorted' or even ignored by the learner, depending on his or her perceptions, habitual learning approach and metacognitive learning conceptions. In addition, establishing a positive learning environment is necessary for the implementation of an effective instructional program (Cannon 1995).

Researchers and teachers have found it useful to employ classroom climate dimensions as criteria of effectiveness in curriculum evaluation because they have differentiated revealingly between alternative curricula when student outcome measures have shown little sensitivity (Fraser et al. 1987). For example, by incorporating a classroom environment instrument within an evaluation of the use of a computerised database, Maor and Fraser (1996) found that students perceived that their classes became more inquiry-oriented during the use of the innovation. Similarly, in Singapore, classroom environment measures were used as dependent variables in an evaluation of computer-assisted learning by Teh and Fraser (1994).

Martin-Dunlop and Fraser (2008) evaluated an innovative science course for prospective elementary teachers in a large urban university in California. When learning environment scales selected from the What Is Happening In this Class? (WIHIC) and Science Laboratory Environment Inventory (SLEI) were administered to 525 females in 27 classes, very large differences were found 
on all scales (of over 1.5 standard deviations) between students' perceptions of the innovative course and their previous courses.

In a study 761 high-school biology student in south-eastern USA, Lightburn and Fraser (2007) used the SLEI in an evaluation of the effectiveness of using anthropometric activities. Relative to a comparison group, the anthropometry group had significantly higher scores on some SLEI and attitude scales.

Aldridge and Fraser (2008) used the Technology-Rich Outcomes-Focused Learning Environment Instrument (TROFLEI) in monitoring and evaluating the success of an innovative new senior high school in Western Australia in promoting outcomes-focused education. The sample included 449 students in 2001, 626 students in 2002, 471 students in 2003 and 372 students in 2004. Changes in student perceptions of the classroom environments over the 4 years supported the efficacy of the school's educational programs in that changes were statistically significant and of moderate magnitude (with effect sizes ranging from 0.20 to 0.38 standard deviations) for seven of the ten TROFLEI scales.

Pickett and Fraser (2009) argued that the litmus test of the success of any teacher professional development program is the extent of changes in teaching behaviours and ultimately student outcomes in the participating teachers' school classrooms. Consequently, their evaluation of a two-year mentoring program in science for beginning elementary-school teachers drew on the field of learning environments in gauging this program's success in terms of participants' classroom teaching behaviour as assessed by their school students' perceptions of their classroom learning environments. The sample consisted on seven beginning grade 3-5 teachers in south-eastern USA and their 573 elementary-school students. A modified version of the WIHIC was used to assess student perceptions of classroom learning environment as a pretest and a posttest. Use of MANOVA and effect sizes supported the efficacy of the mentoring program in terms of some improvements over time in the classroom learning environment, as well as in students' attitudes and achievement. 
Nix, Fraser and Ledbetter (2005) used the Constructivist Learning Environment Survey (CLES) in their evaluation of an innovative science teacher development program (based on the Integrated Science Learning Environment model) in terms of the types of school classroom environments created by these teachers as perceived by their 445 students in 25 classes. For this evaluation, Nix and colleagues evolved an innovative side-by-side response format for the CLES so that students could provide their perceptions of THIS classroom (the students' current class with the teacher who had experienced the professional development) and OTHER classroom (other classes at the same school taught by different teachers). Students of teachers who had experienced the professional development perceived their classrooms as having appreciably higher levels of the CLES scales of Personal Relevance and Uncertainty relative to the comparison classes.

In New York, Wolf and Fraser (2008) evaluated the effectiveness of using inquiry-based laboratory activities in terms of learning environment, attitudes, and achievement. Administration of the WIHIC to 1,434 middle-school science students in 71 classes supported the validity of the WIHIC and analyses for a sub-sample of students revealed that inquiry instruction promoted more Student Cohesiveness than non-inquiry instruction (effect size of one-third of a standard deviation). As well inquiry-based instruction was differentially effective for male and female students.

In Singapore, Khoo and Fraser (2008) adapted the WIHIC for use in the evaluation of adult computer application courses. Scales such as Teacher Support were renamed Trainer Support. The sample consisted of 250 working adults (a population seldom researched in past learning environment studies) attending five computer education centres in Singapore. Various analyses supported the factorial validity and reliability of the WIHIC when used with this adult sample in the Singaporean context. Generally students perceived their classroom environments positively, with this pattern varying only a little for students of different sexes and ages. However, males perceived significantly more Involvement, whereas females perceived more Equity. Also, whereas males' perceptions of 
Trainer Support were independent of age, older females had more positive perceptions than younger females.

In Walberg's (1981) multi-factor psychological model of educational productivity, classroom psychosocial environment plays an important role in the learning process. Empirical research based on this educational productivity model revealed that, among other factors, the classroom and school environment is a strong predictor of both achievement and attitude outcomes, even when a comprehensive set of other factors was held constant (Fraser 1998a).

What matters is the appreciation and usefulness of instructional practices from the learner's point of view. Because perceptions of the learning environment influence how a learner learns (Ramsden 1992), this study focused on the perspectives of the learners who interpret the learning environment (Bednar et al. 1991; Cunningham 1991; Salomon 1998).

Hence, we instigated an evaluation of MMD based on the learners' perceptions, as it is ultimately the learners who interpret the learning environment (Duffy and Cunningham 1996; Salomon 1998). By involving the learners themselves, this study provided valuable information through the eyes of the learners, as opposed to data obtained by an external observer, as in the case of classroom observation. Therefore, we adopted Entwistle's (1991) stand that it is the students' perceptions of the learning environment that influence how a student learns.

The field of learning environment provides a rich array of useful instruments (Fraser, 2002) that have been validated across the world over the past several decades. We found this field to be an appropriate framework for the evaluation of the effectiveness of the MMD pedagogical model in this study. In the field of learning environment, research has grown dramatically over the previous few decades, with classroom environment assessments having been used as both dependent and independent variable for a wide variety of research purposes (Fisher and Khine 2006; Fraser 1998a, 2007, 2012; Goh and Khine, 2002). 
There is abundant research on learning environments which primarily focused on the link between learners' perceptions of their learning environments and outcomes (Fraser 1998c, 2012). While past learning environment research (Fraser, 2012) has encompassed numerous different school subjects, especially science, our research appears to represent the first use of learning environment instruments with students studying business subjects.

In our study, we compared the learner-perceived effectiveness of two types of learning environments, namely, the traditional teacher-talk whole-group instructional environment and one that involved a variety of MMD strategies and activities in a constructivist learning environment. Because our study involved the separate assessment of actual and preferred environment, our evaluation of MMD could be based on the degree of alignment or congruence between the actual environment and students' preferred learning environment.

This study was guided by two research questions. First, is a questionnaire for assessing actual and preferred classroom environment valid and reliable when used with secondary business students in Singapore? Second, is the use of the Mixed Mode Delivery model with preservice teachers effective in terms of congruence between actual and preferred learning environments in their students' school classrooms during the practicum?

\section{Significance of the study}

This study makes a contribution to the field of learning environment research as it is the first time that learning environment ideas have been applied with business studies subjects. Also our research represents the first empirical study using a Mixed Mode Delivery framework and no known past studies have attempted to evaluate the use of this instructional approach. 
The results from this study have the potential to provide insights into whether the MMD is an effective pedagogical model in terms of learners' perceptions of the classroom environment and likely to contribute to: knowledge for the region's educators about the effectiveness of the types of learning environments created through the use of the MMD; and suggested strategies to help teachers and preservice teachers to effectively build a conducive learning environment for capitalising on new knowledge technologies to meet the needs of different types of learners.

\section{Research Methods}

Samples and phases of the study

A combination of purposive and stratified sampling methods was employed in this study. Purposive or purposeful sampling (Merriam 1998) is a non-probabilistic method that assumes that the researcher wants to discover, understand, gain insight and choose a sample which will lead to the most understanding. Consequently, the samples involved in this study were composed of willing and chosen participants from various Singapore government schools that offer business education.

A total of 2216 secondary school students in 82 business classes taught by the presservice teachers using the MMD during field experience responded to both actual and preferred forms of a classroom environment questionnaire. Another sample of over 991 secondary school students in 32 business classes taught by the preservice teachers using conventional, whole-class instruction and teacher talk methods (TA) during field experience responded to both actual and preferred forms of a classroom environment questionnaire. During each data-collection phase, preservice teachers administered surveys to their school students during their 10-week practicum.

\section{Instrument}


School students' perceptions of their classroom environments were assessed using a version of the Constructivist Learning Environment Survey (CLES) (Taylor et al. 1995, 1997), which assesses Personal Relevance, Uncertainty, Critical Voice, Shared Control and Student Negotiation. The CLES was developed to enable educators and researchers to measure students' perceptions of the extent to which constructivist approaches are present in classrooms (Taylor et al. 1997). The CLES incorporates a critical theory perspective on the socio-cultural framework of the classroom learning environment (Grundy 1987; Habermas 1972, 1984). The CLES was selected for our study because of its ability to characterise specific dimensions of the constructivist learning environment and because it has demonstrated strong factorial validity and reliability in numerous countries (Fraser 2012). Table 1 summarises the values of the alpha reliability coefficient obtained in past research in five countries.

Table 1 about here

For example, Taylor and his colleagues (1999) reported sound factorial validity and internal consistency reliability for the CLES for samples of: 494 Australian 13 year-olds in 41 grade 8 and 9 classes in 13 schools involved in an optional component of the Third International Mathematics and Science Study (TIMSS); and 1,600 grade 9-12 science students in Texas.

When Johnson and McClure (2004) used the same original 30-item version of the CLES in the USA with 290 upper-elementary, middle-school and high-school teachers and preservice teachers, they also reported strong factorial validity and reliability. Nevertheless, Johnson and McClure developed a shorter and modified 20-item version of the CLES containing the same five scales. For a different sample of teachers and students at the upper-elementary, middle-school and high-school levels, Johnson and McClure reported that the new and more economical version of the CLES exhibited strong validity and reliability.

In a cross-national study of junior high-school science classroom learning enviroments, the English version of the CLES was administered to 1,081 students in 50 classes in Australia while a 
Mandarin translation was administered to 1,879 students in 50 classes in Taiwan. Aldridge, Fraser, Taylor and Chen (2000) reported sound validity (factor structure, reliability and ability to differentiate between classrooms) for both English and Mandarin versions of the CLES. Additionally, these researchers reported that Australian classes were perceived as being more constructivist than Taiwanese classes (especially in terms of Critical Voice and Student Negotiation).

Peiro and Fraser (2009) modified the CLES, translated it into Spanish, and administered the English and Spanish versions to 739 grade K-3 science students in Miami, USA. Analyses supported the validity of the modified English and Spanish versions when used with these young children. Strong and positive associations were found between students' attitudes and the nature of the classroom environment, and a three-month classroom intervention led to large and educationally important changes in classroom environment.

In South Africa, Aldridge, Fraser and Sebela (2004) administered the English version of the CLES to 1,864 grade 4-6 mathematics learners in 43 classes. This led to the cross-validation of this version of the CLES for this population in terms of factorial validity, internal consistency reliability and ability to differentiate between classrooms. The primary focus of this study was to assist South African teachers to become more reflective practitioners in their daily classroom teaching. Through the use of the CLES in teacher action research, some improvements in the constructivist orientation of classrooms were achieved during a 12 -week intervention.

When Kim, Fisher and Fraser (1999) translated the CLES into the Korean language and crossvalidated it with a sample of 1,083 students in 24 grade 10 science classes, results supported the factor structure and reliability of the Korean version, revealed statistically significant relationships between classroom environment and students' attitudes to science, and confirmed that students exposed to a new curriculum perceived a more constructivist learning environment than did students who had not been exposed to this curriculum. 
In a study in Florida, Spinner and Fraser (2005) used the CLES with two separate samples of 53 and 66 grade 5 students undertaking an innovative mathematics program called the Class Banking System (CBS). As well as cross-validating the CLES, these researchers reported that, relative to nonCBS students, CBS students experienced more favourite pretest-posttest changes on most of the dimensions of the CLES.

Working with a diverse sample of 1,079 students in 59 science classes in North Texas, Nix, Fraser and Ledbetter (2005) reported strong support for the validity of the CLES. Following the removal of four items, each of the remaining 26 items had a factor loading of at least 0.40 on its own scale and less than 0.40 on all other scales, with a total of $45.5 \%$ of the variance being accounted for. All CLES scales were capable of differentiating significantly between the perceptions of students in different classes. An evaluation of an innovative science teacher professional development program (known as the Integrated Science Learning Environment, ISLE, model) revealed that the students of these teachers perceived their classrooms more favourably than did the students of other teachers. In a follow-up study in Texas, Nix and Fraser (2010) used Johnson and McLure's (2004) newer and shorter 20-item version of the CLES in an evaluation of the implementation of the ISLE model over three semesters involving 17 teachers and 845 students. Use of CLES and qualitative data revealed that changing teachers' learning environment at the university level fostered similar changes in their students' middle-school classroom environments.

We used a modified and more economical version of the CLES in which we retained all of the original five scales, each of which measured students' perceptions of the learning environment created by the preservice teachers. However, to reduce administration time, the number of items in each CLES scale was reduced from 6 to 4 items. Each item has a five-point frequency response scale with the responses of Very Often, Often, Sometimes, Seldom and Never. The students responded to both the perceived (actual) and preferred forms of the modified CLES.

\section{Data analysis}


Data from the questionnaire survey were analysed using the SPSS program. To answer the first research question about the validity of the modified CLES when used with business studies students in Singapore, principal axis factor analysis with varimax rotation and Kaiser normalization was conducted to check and refine the factor structure. The Cronbach alpha reliability coefficient was used as an index of scale internal consistency. Analysis of variance (ANOVA) was used to judge the ability of the actual form of each learning environment scale to differentiate between the perceptions of students in different classrooms. A discriminant validity index (namely, the mean correlation of a scale with other scales) was used to indicate whether each scale measures a separate dimension that is distinct from the other scales in the same questionnaire.

To address Research Question 2 concerning the effectiveness of the MMD model in terms of classroom environment, MANOVA was used to compare MMD and TA groups in terms of the magnitude of the gaps between actual and preferred learning environment scores. Because there were numerous learning environment variables in this study, MANOVA was used to reduce the risk of committing Type I errors. Because the multivariate test using Wilks' lambda criterion revealed significant results overall for the whole set of learning environment variables, the univariate ANOVA results were interpreted for each learning environment scale separately. Students' responses to the set of CLES scales constituted the dependent variables and the form of the questionnaire (actual and preferred) formed the independent variable.

Whereas MANOVA and ANOVA were used to investigate the statistical significance of the differences between school students' actual and preferred classroom environment perceptions, effect sizes were used to indicate the magnitude or educational importance of these differences. Effect sizes, which were calculated by dividing the difference between the actual and preferred mean for a CLES scale by the pooled standard deviation, express differences in standard deviation units (Cohen, 1988; Thompson, 1998). 


\section{Results}

\section{Validation of CLES}

We conducted a principal axis factor analysis separately for actual and preferred data for the experimental MMD sample of 2,216 students in 82 classes and separately for actual and preferred data for the control group of 991 students in 32 classes. The criteria for the retention of any item were that it must have a factor loading of at least 0.40 with its own scale and less than 0.40 with each of the other scales. The factor loadings obtained for each of the four analyses are shown in Table 2.

Insert Table 2 About Here

Table 2 shows that, with the exception of Item 3 from the Personal Relevance scale, all items had loadings that were greater than 0.40 with their own scale and less than 0.40 with the other four scales. The bottom of Table 2 shows the eigenvalue and percentage of variance for each scale for each factor analysis. For example, the total proportion of variance accounted for was $67 \%$ for the actual form and $68 \%$ for the preferred form for the experimental sample.

For the same sample, the Cronbach alpha coefficient was estimated for each CLES scale for two units of analysis, namely, the student and the class mean. Table 3 shows the alpha reliability for both the actual and preferred forms of each scale of the learning environment were consistently high, ranging from 0.83 to 0.93 for actual form and from 0.83 to 0.95 for the preferred form with the student as the unit of analysis. With the class mean as the unit of analysis, alpha coefficients ranged from 0.88 to 0.96 for the actual form and from 0.84 to 0.95 for the preferred form.

Insert Table 3 About Here 
Table 3 also reports data for the independence or discriminant validity of CLES scales. Using the individual student as the unit of analysis, the discriminant validity results (mean correlation of a scale with other scales) for the five scales of the modified CLES ranged from 0.33 to 0.43 for the actual and from 0.32 to 0.45 for the preferred form. When the class mean was employed as the unit of analysis, the mean correlation ranged from 0.44 to 0.73 for actual form and ranged from 0.46 to 0.66 for preferred form. Again, these scores indicate that, although each scale of the modified CLES does overlap with other scales, relatively distinct aspects of the learning environment are being assessed. Furthermore, the factor analysis results support the independence of factor scores on the five scales of the modified CLES.

A one-way analysis of variance (ANOVA) was performed for the actual version of each CLES scale to provide evidence of the ability of each scale to differentiate significantly between the perceptions of students in different classrooms. This characteristic was examined for each scale with class membership as the main effect and using individual scores as the unit of analysis. The eta ${ }^{2}$ statistic, which represents the proportion of variance attributable to class membership, ranged from 0.17 to 0.25 for different CLES scales. All scales differentiated significantly $(p<0.01)$ between classroom (Table 3). Thus, learners in the same class perceived their learning environment in a relatively similar manner, while the mean perceptions of learners in different classes vary across classes.

Overall the data presented above support the contention that the modified CLES is a valid and reliable learning environment instrument for the assessment of secondary students' perceptions of psychosocial learning environments in business studies in Singapore.

\section{Effectiveness of MMD}

To answer the second research question, MANOVA was used to investigate the effectiveness of MMD in terms of differences between actual and preferred scores on the CLES separately for two 
different instructional groups (MMD and a comparison instructional approach). In order to avoid increasing the risk of committing a Type I error, the individual ANOVA for each CLES scale was interpreted only after the multivariate test (Wilks' lambda criterion) yielded significant results for the set of five CLES scales as a whole. Also, effect sizes were used to express the magnitude of actualpreferred differences on each CLES scale in terms of standard deviation units. The effect size was calculated for a scale by dividing the differences between the actual and preferred means by the pooled standard deviation (Cohen, 1988; Thompson, 1988).

Table 4 provides, separately for each CLES scale and separately for each instructional group (MMD and TA), the average item mean (i.e. the scale mean divided by the number of items), the average item standard deviation, and two statistics for the difference between actual and preferred scores (the effect size and the results from ANOVA). Generally, the results in Table 4 indicate large and statistically significant differences between students' actual and preferred learning environment perceptions on nearly all CLES scales and for both the MMD and TA groups. Differences between actual and preferred scores were statistically significant $(p<0.01)$ for every CLES scale for the TA group and for all CLES scales except Uncertainty for the MMD group. This pattern of results, in which students would prefer a more favourable classroom environment than what they perceive to be actually present, replicates decades of past research around the world (Fisher and Fraser 1983a; Fraser 1998a, 2012).

Insert Table 4 About Here

With the exception of the Uncertainty scale for the MMD group, for which the effect size for actual-preferred differences is only 0.19 standard deviations, the other effect sizes in Table 4 range from 0.46 to 1.88 standard deviations and are considered large according to Cohen's (1988) criteria.

However a striking pattern that is evident in the results in Table 4 is that, although both the MMD and TA students reported sizeable gaps between the actual environment and what they would 
prefer, the effect sizes for the TA group (ranging from 0.52 to 1.88 standard deviations) are considerably larger than the effect sizes for the MMD group (ranging from 0.19 to 0.74 standard deviations). This pattern supports the efficacy of the MMD in that MMD teachers, relative to TA teachers, had succeeded in promoting actual school classroom environments that were perceived by their students to be more congruent with students' preferences.

\section{Conclusion and recommendations}

This study achieved two main objectives. Firstly, various analyses (e.g. factor analysis and reliability analysis) attested to validity of the Constructivist Learning Environment Survey (CLES) when used in Singapore with secondary business studies students. Secondly, an evaluation of the Mixed Mode Delivery (MMD), in terms of gaps between the actual environment and what students would prefer, revealed that effect sizes for a comparison group (ranging from 0.52 to 1.88 standard deviations for different CLES scales) were considerably larger than the effect sizes for the MMD group (ranging from 0.19 to 0.74 standard deviations). This pattern supports the efficacy of the MMD in that MMD teachers, relative to comparison teachers, had achieved actual school classroom environments that were perceived by their students to be more congruent with students' preferences.

In future research, the learning environment instrument validated in this study could be used in other research in business education and in Singapore. For example, researchers could explore the relationship between preservice teachers' or beginning teachers' sense of self-efficacy and their commitment to the emotionally-demanding task of engaging their students in renegotiating the social reality of the learning environment. A study could be carried out to find out if the gap between the actual and preferred learning environment of the students is related to teachers' self-efficacy and attitude scores. Also this questionnaire could be used with business education students in Singapore in studies that replicate common lines of past learning environment research (Fraser 2012), including investigations of associations between student outcomes and the classroom environment, evaluations 
of educational innovations, and teachers' action research attempts to improve the learning environments of their own classrooms.

\section{REFERENCES}

Aldridge, J.M., \& Fraser, B.J. (2008). Outcomes-focused learning environments: Determinants and effects (Advances in Learning Environments Research series). Rotterdam, The Netherlands: Sense Publishers.

Aldridge, J.M., Fraser, B.J., \& Sebela, M.P. (2004). Using teacher action research to promote constructivist learning environments in South Africa. South African Journal of Education, 24, 245-253.

Aldridge, J.M., Fraser, B.J., Taylor, P.C., \& Chen, C.C. (2000). Constructivist learning environments in a cross-national study in Taiwan and Australia. International Journal of Science Education, $22,37-55$.

Andrews, J., Garrison, D.R., \& Magnusson, K. (1996). The teaching and learning transaction in higher education: A study of excellent professors and their students. Teaching in Higher Education, 1, 81-103.

Bednar, A.K., Cunningham, D., Duffy, T.M., \& Perry, J.D. (1991). Theory into practice: How do we link? In G.L. Anglin (Ed.), Instructional technology: Past, present, and future (pp. 88-101). Englewood, CO: Libraries Unlimited.

Cannon, J.R. (1995). Further validation of the Constructivist Learning Environment Survey: Its use in the elementary science methods course. Journal of Elementary Science Education, 7(1), 4762.

Cohen, J. (1988). Statistical power analysis for the behavioral sciences $\left(2^{\text {nd }}\right.$ ed.). Hillsdale, NJ: Erlbaum.

Cunningham, J.D. (1991). Assessing constructions and constructing assessments: A dialogue. Educational Technology, 5, 13-17. 
Duit, R., \& Treagust, D.F. (1995). Students' conceptions and constructivist teaching approaches. In B.J. Fraser \& H.J. Walberg (Eds.), Improving science education (pp. 46-69). Chicago: National Society for the Study of Education.

Duffy, T.M., \& Cunningham, D.J. (1996). Constructivism: Implications for the design and delivery of instruction. In D.H. Jonassen (Ed.), Handbook of research on educational communications and technology (pp. 170-198). New York: Scholastic.

Entwistle, N.J. (1991). Approaches to learning and perceptions of the learning environment Introduction to the special issue. Higher Education, 23, 201-204.

Fisher, D.L., \& Khine, M.S. (Eds.). (2006). Contemporary approaches to research on learning environments: Worldviews. Singapore: World Scientific.

Fraser, B.J. (1994). Research on classroom and school climate. In D.L. Gabel (Ed.), Handbook of research on science teaching and learning (pp. 493-541). New York: Macmillan.

Fraser, B.J. (1998a). The birth of a new journal: Editor's introduction. Learning Environments Research, 1, 1-5.

Fraser, B.J. (1998b). Classroom environment instruments: Development, validity and applications. Learning Environments Research: An International Journal, 1, 7-33.

Fraser, B.J. (1998c). Science learning environments: Assessment, effects and determinants. In B.J. Fraser \& K.G. Tobin (Eds.), International handbook of science education (pp. 527-564). Dordrecht, The Netherlands: Kluwer Academic Publisher.

Fraser, B.J. (2002). Learning environment research: Yesterday, today and tomorrow. In S. C. Goh \& M. S Khine (Eds.), Studies in educational learning environments: An international perspective (pp. 1-26). Singapore: World Scientific.

Fraser, B.J. (2007). Classroom learning environments. In S.K. Abell \& N.G. Lederman (Eds.), Handbook of research on science education (pp. 103-124). Mahwah, NJ: Lawrence Erlbaum. Fraser, B.J. (2012). Classroom learning environments: Retrospect, context and prospect. In B.J. Fraser, K.G. Tobin and C.J. McRobbie (Eds.), Second international handbook of science education (pp. 1191-1239). New York: Springer. 
Fraser, B.J., Williamson, J.C., \& Tobin, K. (1987). Use of classroom and school climate scales in evaluating alternative high schools. Teaching and Teacher Education, 3, 219-231.

Goh, S.C., \& Khine, M.S. (Eds.). (2002). Studies in educational learning environments: An international perspective. Singapore: World Scientific.

Grundy, S. (1987). Curriculum: Product or praxis. New York: The Falmer Press.

Habermas, J. (Ed.). (1972). Knowledge and human interests (2nd ed.). London: Heinemann.

Habermas, J. (Ed.). (1984). A theory of communicative action: Vol 1. Boston, MA: Beacon Press.

Johnson, B., \& McClure, R. (2004). Validity and reliability of a shortened, revised version of the Constructivist Learning Environment Survey (CLES). Learning Environments Research, 7, 65-80.

Kim, H.B., Fisher, D.L., \& Fraser, B.J. (1999). Assessment and investigation of constructivist science learning environments in Korea. Research in Science and Technological Education, 17, 239249.

Koh, N.K. (2004, Decembr). The authentic evaluation of teachers using the mixed-mode assessment model. Paper presented at the International Conference on Teaching and Learning in Higher Education, National University of Singapore, Singapore.

Khoo, H.S., \& Fraser, B.J. (2008). Using classroom psychosocial environment in the evaluation of adult computer application courses in Singapore. Technology, Pedagogy and Education, 17, $67-81$.

Lightburn, M.E., \& Fraser, B.J. (2007). Classroom environment and student outcomes among students using anthropometry activities in high school science. Research in Science and Technological Education, 25, 153-166.

Maor, D., \& Fraser, B.J. (1996). Use of classroom environment perceptions in evaluating inquirybased computer assisted learning. International Journal of Science Education, 18, 401-421.

Martin-Dunlop, C., \& Fraser, B.J. (2008). Learning environment and attitudes associated with an innovative course designed for prospective elementary teachers. International Journal of Science and Mathematics Education, 6, 163-190. 
Merriam, S. (1998). Qualitative research and case study applications in education. San Francisco, CA: Jossey-Bass Publishers.

Nix, R.K., \& Fraser, B.J. (2010). Using computer-assisted teaching to promote constructivist practices in teacher education. In B.A. Morris and G.M. Ferguson (Eds.), Computer-assisted teaching: New developments (pp. 93-115). New York: Nova Science Publisher.

Nix, R.K., Fraser, B.J., \& Ledbetter, C.E. (2005). Evaluating an integrated science learning environment using the Constructivist Learning Environment Survey. Learning Environments Research, 8, 109-133.

Peiro, M.M., \& Fraser, B.J. (2009). Assessment and investigation of science learning environments in the early childhood grades. In M. Ortiz and C. Rubio (Eds.), Educational evaluation: 21st century issues and challenges (pp. 349-365). New York: Nova Science Publishers.

Pickett, L.H., \& Fraser, B.J. (2009). Evaluation of a mentoring program for beginning teachers in terms of the learning environment and student outcomes in participants' school classrooms. In A. Selkirk and M. Tichenor (Eds.), Teacher education: Policy, practice and research (pp. 115). New York: Nova Science Publishers.

Rainer, J.D., \& Matthews, M.M. (2002). Ownership of learning in teacher education. Action in Teacher Education, 24 (1), 22-30.

Ramsden, P. (1992). Learning to teach in higher education. London: Routledge.

Salomon, G. (1998). Novel constructivist learning environments and novel technologies: Some issues to be concerned with. Research Dialogue in Learning and Instruction, 1, 3-12.

Spinner, H., \& Fraser, B.J. (2005). Evaluation of an innovative mathematics program in terms of classroom environment, student attitudes, and conceptual development. International Journal of Science and Mathematics Education, 3, 267-293.

Tapscott, D. (1997). Growing up digital: The rise of the net generation. New York: McGraw-Hill. Taylor, P.C., Dawson, V., \& Fraser, B.J. (1995, April). Classroom learning environments under transformation: A constructivist perspective. Paper presented at the annual meeting of the American Educational Research Association, San Francisco, CA. 
Taylor, P.C., Fraser, B.J., \& Fisher, D.L. (1997). Monitoring constructivist classroom learning environments. International Journal of Educational Research, 27, 293-302.

Teh, G., \& Fraser, B.J. (1994). An evaluation of computer-assisted learning in terms of achievement, attitudes and classroom environment. Evaluation and Research in Education, 8, 147-161.

Thompson, B. (1998). Review of 'What if there were no significance tests?' Educational Psychological Measurement, 58, 334-346.

Wolf, S.J., \& Fraser, B.J. (2008). Learning environment, attitudes and achievement among middleschool science students using inquiry-based laboratory activities. Research in Science Education, 38, 321-341. 
Table 1 Internal consistency (Cronbach alpha coefficient) for CLES in past research in five countries

\begin{tabular}{lccccc}
\hline \multirow{2}{*}{ Scale } & \multicolumn{5}{c}{ Alpha reliability coefficient } \\
\cline { 2 - 6 } & Taiwan $^{\mathrm{a}}$ & Australia $^{\mathrm{a}}$ & Korea $^{\mathrm{b}}$ & South Africa $^{\mathrm{c}}$ & USA $^{\mathrm{d}}$ \\
\hline Personal Relevance & 0.87 & 0.88 & 0.78 & 0.61 & 0.75 \\
Uncertainty & 0.83 & 0.76 & 0.79 & 0.60 & 0.74 \\
Critical Voice & 0.73 & 0.85 & 0.80 & - & 0.77 \\
Shared Control & 0.92 & 0.91 & 0.87 & 0.63 & 0.84 \\
Student Negotiation & 0.85 & 0.89 & 0.84 & 0.63 & 0.85 \\
\hline
\end{tabular}

${ }^{\text {a }}$ Source: Aldridge et al. (2000)

${ }^{\mathrm{b}}$ Source: Kim et al. (1999)

${ }^{\mathrm{c}}$ Source: Aldridge et al. (2004). This study used 4 CLES scales only.

${ }^{\mathrm{d}}$ Source: Nix et al. (2005) 
Table 2 Factor analysis results for actual and preferred forms of modified CLES for experimental and control students

\begin{tabular}{|c|c|c|c|c|c|c|c|c|c|c|c|c|c|c|c|c|c|c|c|c|}
\hline \multirow{4}{*}{$\begin{array}{l}\text { Item } \\
\text { Number }\end{array}$} & \multicolumn{20}{|c|}{ Factor Loadings } \\
\hline & \multicolumn{4}{|c|}{ Personal Relevance } & \multicolumn{4}{|c|}{ Uncertainty } & \multicolumn{4}{|c|}{ Critical Voice } & \multicolumn{4}{|c|}{ Shared Control } & \multicolumn{4}{|c|}{ Negotiation } \\
\hline & \multicolumn{2}{|c|}{ Experimental } & \multicolumn{2}{|c|}{ Control } & \multicolumn{2}{|c|}{ Experimental } & \multicolumn{2}{|c|}{ Control } & \multicolumn{2}{|c|}{ Experimental } & \multicolumn{2}{|c|}{ Control } & \multicolumn{2}{|c|}{ Experimental } & \multicolumn{2}{|c|}{ Control } & \multicolumn{2}{|c|}{ Experimental } & \multicolumn{2}{|c|}{ Control } \\
\hline & Act & Pref & Act & Pref & Act & Pref & $\overline{\text { Act }}$ & Pref & Act & Pref & $\overline{\text { Act }}$ & Pref & Act & Pref & $\overline{\text { Act }}$ & Pref & Act & Pref & $\overline{\mathrm{Act}}$ & Pref \\
\hline PR1 & 0.82 & 0.80 & 0.71 & 0.67 & & & & & & & & & & & & & & & & \\
\hline PR2 & 0.70 & 0.63 & 0.51 & 0.44 & & & & & & & & & & & & & & & & \\
\hline PR4 & 0.76 & 0.77 & 0.68 & 0.72 & & & & & & & & & & & & & & & & \\
\hline U5 & & & & & 0.68 & 0.75 & 0.56 & 0.61 & & & & & & & & & & & & \\
\hline U6 & & & & & 0.74 & 0.78 & 0.43 & 0.47 & & & & & & & & & & & & \\
\hline U7 & & & & & 0.77 & 0.75 & 0.68 & 0.66 & & & & & & & & & & & & \\
\hline U8 & & & & & 0.70 & 0.68 & 0.64 & 0.59 & & & & & & & & & & & & \\
\hline CV9 & & & & & & & & & 0.75 & 0.77 & 0.60 & 0.66 & & & & & & & & \\
\hline CV10 & & & & & & & & & 0.76 & 0.77 & 0.66 & 0.79 & & & & & & & & \\
\hline CV11 & & & & & & & & & 0.68 & 0.68 & 0.55 & 0.42 & & & & & & & & \\
\hline CV12 & & & & & & & & & 0.66 & 0.67 & 0.65 & 0.48 & & & & & & & & \\
\hline $\mathrm{SC} 13$ & & & & & & & & & & & & & 0.71 & 0.67 & 0.55 & 0.60 & & & & \\
\hline SC14 & & & & & & & & & & & & & 0.78 & 0.75 & 0.64 & 0.74 & & & & \\
\hline SC15 & & & & & & & & & & & & & 0.83 & 0.81 & 0.83 & 0.75 & & & & \\
\hline SC16 & & & & & & & & & & & & & 0.79 & 0.79 & 0.72 & 0.66 & & & & \\
\hline N17 & & & & & & & & & & & & & & & & & 0.77 & 0.77 & 0.72 & 0.71 \\
\hline N18 & & & & & & & & & & & & & & & & & 0.83 & 0.82 & 0.88 & 0.79 \\
\hline N19 & & & & & & & & & & & & & & & & & 0.78 & 0.81 & 0.47 & 0.59 \\
\hline $\mathrm{N} 20$ & & & & & & & & & & & & & & & & & 0.73 & 0.71 & 0.64 & 0.63 \\
\hline$\%$ Variance & 5.40 & 5.46 & 5.52 & 6.01 & 9.27 & 7.74 & 6.96 & 7.71 & 6.80 & 5.73 & 8.28 & 6.85 & 35.54 & 9.02 & 10.42 & 32.17 & 9.87 & 40.48 & 34.54 & 10.26 \\
\hline Eignevalues & 1.03 & 1.04 & 1.05 & 1.14 & 1.76 & 1.47 & 1.32 & 1.47 & 1.30 & 1.09 & 1.59 & 1.30 & 6.80 & 1.72 & 2.09 & 6.11 & 1.88 & 7.69 & 6.56 & 1.95 \\
\hline
\end{tabular}

Factor loadings less than 0.4 have been omitted.

Principal axis factor analysis with varimax rotation and Kaiser normalisation

$N=2216$ students in 82 classes (experimental group) and 991 students in 32 classes (control group) 
Table 3 Internal consistency reliability (Cronbach alpha coefficient) and discriminant validity (mean correlation with other scales) for actual and preferred forms for two units of analysis, and ANOVA results for ability of actual form to differentiate between classrooms for modified CLES with MMD students

\begin{tabular}{|c|c|c|c|c|c|c|c|}
\hline \multirow[t]{2}{*}{ Scale } & \multirow[t]{2}{*}{$\begin{array}{l}\text { No. of } \\
\text { items }\end{array}$} & \multirow[t]{2}{*}{ Unit of analysis } & \multicolumn{2}{|c|}{ Alpha reliability } & \multicolumn{2}{|c|}{$\begin{array}{l}\text { Mean correlation } \\
\text { with other scales }\end{array}$} & \multirow{2}{*}{$\begin{array}{c}\text { ANOVA } \\
\text { eta }^{2} \\
\text { Act }\end{array}$} \\
\hline & & & Act & Pref & Act & Pref & \\
\hline \multirow{2}{*}{ Personal Relevance } & \multirow{2}{*}{3} & Student & 0.76 & 0.75 & 0.39 & 0.45 & \multirow[t]{2}{*}{$0.20^{*}$} \\
\hline & & Class & 0.93 & 0.84 & 0.66 & 0.68 & \\
\hline \multirow{2}{*}{ Uncertainty } & \multirow{2}{*}{4} & Student & 0.79 & 0.81 & 0.42 & 0.45 & \multirow[t]{2}{*}{$0.25^{*}$} \\
\hline & & Class & 0.90 & 0.90 & 0.63 & 0.54 & \\
\hline \multirow{2}{*}{ Critical Voice } & \multirow{2}{*}{4} & Student & 0.78 & 0.82 & 0.43 & 0.50 & \multirow{2}{*}{$0.17 * *$} \\
\hline & & Class & 0.88 & 0.92 & 0.63 & 0.62 & \\
\hline \multirow{2}{*}{ Shared Control } & \multirow{2}{*}{4} & Student & 0.88 & 0.89 & 0.46 & 0.53 & \multirow[t]{2}{*}{$0.21 * *$} \\
\hline & & Class & 0.96 & 0.95 & 0.67 & 0.69 & \\
\hline \multirow{2}{*}{ Negotiation } & \multirow{2}{*}{4} & Student & 0.84 & 0.86 & 0.39 & 0.47 & \multirow[t]{2}{*}{$0.19 * *$} \\
\hline & & Class & 0.94 & 0.94 & 0.55 & 0.65 & \\
\hline
\end{tabular}

The sample size was 2216 students in 82 classes.

$\mathrm{Eta}^{2}$ is the ratio between the total sum of squares and represents the proportion of variance accounted for by class membership. 
Table 4 Average item mean, average item standard deviation and difference between actual and preferred environment (effect size and MANOVA with repeated measures) for the CLES using the class mean as the unit of analysis

\begin{tabular}{|c|c|c|c|c|c|c|c|}
\hline \multirow[t]{2}{*}{ Scale } & \multirow[t]{2}{*}{ Group } & \multicolumn{2}{|c|}{$\begin{array}{c}\text { Average item } \\
\text { mean }\end{array}$} & \multicolumn{2}{|c|}{ Average item SD } & \multicolumn{2}{|l|}{ Difference } \\
\hline & & Actual & Preferred & Actual & Preferred & Effect size & $F$ \\
\hline \multirow[t]{2}{*}{ Personal Relevance } & MMD & 3.23 & 3.48 & 0.37 & 0.31 & 0.74 & $2.32 * *$ \\
\hline & TA & 3.08 & 3.56 & 0.32 & 0.19 & 1.88 & $2.84 * *$ \\
\hline \multirow[t]{2}{*}{ Uncertainty } & MMD & 3.48 & 3.54 & 0.43 & 0.33 & 0.19 & 1.28 \\
\hline & TA & 3.50 & 3.64 & 0.28 & 0.26 & 0.52 & $2.13 * *$ \\
\hline \multirow[t]{2}{*}{ Critical Voice } & MMD & 3.28 & 3.45 & 0.37 & 0.38 & 0.46 & $1.90 * *$ \\
\hline & TA & 3.26 & 3.65 & 0.37 & 0.27 & 1.22 & $2.46^{* * *}$ \\
\hline \multirow[t]{2}{*}{ Shared Control } & MMD & 3.03 & 3.33 & 0.45 & 0.42 & 0.68 & $2.28 * *$ \\
\hline & TA & 2.94 & 3.36 & 0.35 & 0.29 & 1.34 & $2.45^{* *}$ \\
\hline \multirow[t]{2}{*}{ Negotiation } & MMD & 3.33 & 3.54 & 0.41 & 0.39 & 0.52 & $2.20 * *$ \\
\hline & TA & 2.94 & 3.32 & 0.42 & 0.36 & 1.44 & $2.92 * *$ \\
\hline
\end{tabular}

The sample size consisted of 2216 students in 82 classes of MMD teachers and 991 students in 32 classes of TA teachers The effect size is the difference between the actual and preferred means divided by the pooled standard deviation. 